\title{
The Development and Characterization of Polycaprolactone and Titanium Dioxide Hybrids
}

\author{
Mariana Sato de S. B. Monteiro ${ }^{1 *}$, Maria Inês Bruno Tavares ${ }^{2}$ \\ ${ }^{1}$ Faculdade de Farmácia, Universidade Federal do Rio de Janeiro, Rio de Janeiro, Brazil \\ ${ }^{2}$ Instituto de Macromoléculas Professora Eloísa Mano, Universidade Federal do Rio de Janeiro, Rio de Janeiro, Brazil \\ Email: *marianasato@pharma.ufrj.br
}

How to cite this paper: de S. B. Monteiro, M.S. and Tavares, M.I.B. (2018) The Development and Characterization of Polycaprolactone and Titanium Dioxide Hybrids. Advances in Nanoparticles, 7, 11-27.

https://doi.org/10.4236/anp.2018.71002

Received: January 4, 2018

Accepted: February 20, 2018

Published: February 23, 2018

Copyright $\odot 2018$ by authors and Scientific Research Publishing Inc. This work is licensed under the Creative Commons Attribution International License (CC BY 4.0).

http://creativecommons.org/licenses/by/4.0/

\begin{abstract}
Organic/Inorganic hybrid materials have been attracting much attention since they combine the advantages of inorganic materials with the properties of organic polymers. Titanium dioxide nanoparticles $\left(\mathrm{TiO}_{2}\right)$ present good thermal stability, accessibility and catalytic properties. Polycaprolactone (PCL) is a biocompatible and bioresorbable material, which is being examined as biodegradable packaging materials, controlled drug release carriers and other medical applications. Hybrids based on PCL containing different amounts of titanium dioxide nanoparticles, ranging from $0.05 \%$ to $0.35 \% \mathrm{w} / \mathrm{w}$, were prepared using the solution cast method. These systems were characterized by X-ray diffraction (XRD), infrared spectroscopy (FTIR), low-field nuclear magnetic resonance (NMR), thermogravimetric analysis (TG) and differential scanning calorimetry (DSC). The FTIR analysis confirmed that there was an interaction between the PCL chains and the $\mathrm{TiO}_{2}$ nanoparticles. The XRD and DSC analysis showed that the PCL crystallization was affected by $\mathrm{TiO}_{2}$ incorporation, modifying its semi-crystalline structure to a less ordered structure. When $\mathrm{TiO}_{2}$ nanoparticles were added the values of $\mathrm{T}_{1} \mathrm{H}$ and $\mathrm{T}_{1} \rho \mathrm{H}$ increased for all hybrids, therefore, their addition produced a new material with less molecular mobility. In the TG analysis, it was observed that the introduction of $\mathrm{TiO}_{2}$ nanoparticles decreased the thermal resistance of PCL. In DSC analysis, the $\mathrm{PCL} / \mathrm{TiO}_{2}$ hybrids presented a reduction in the crystallization temperature and degree of crystallinity, except for PCL hybrids containing $0.15 \% \mathrm{w} / \mathrm{w}$ of $\mathrm{TiO}_{2}$ nanoparticles.
\end{abstract}

\section{Keywords}

Poly ( $\varepsilon$-Caprolactone), Dioxide Titanium, Hybrids, NMR Relaxometry 


\section{Introduction}

The combination of organic and inorganic structures within a single material at nanoscopic level is one of the most effective approaches for producing new class of hybrids materials with advanced properties. A wide range of nanoparticles such as: clays, carbon nanotubes, graphites, polyhedral oligomeric silsesquioxane and metal oxides are currently available and they are used to prepare these systems [1]. Moreover, the uniform dispersion of these nanofillers produces a large interfacial region between the nanofiller and polymer, due to its high surface area, leading to peculiar characteristics [2].

Thus, organo-inorganic hybrids are defined as complex materials containing both organic and inorganic constituents intimately mixed. The scale of the mixture or the degree of homogeneity may influence the properties of the hybrids, especially when the mixture of the components is adequately achieved on the nanometer scale. These new systems require a detailed characterization of their structure and molecular dynamics, as these factors influence the behavior, properties and stability of these new materials. One of the techniques that can be used to study the molecular dynamics of the polymeric systems is the nuclear magnetic resonance in the solid state through measures of protons relaxation [3] [4].

NMR relaxometry technique has been used by several researchers to measure the nuclear relaxation times, such as: spin-lattice relaxation time in the laboratory frame, spin-lattice relaxation time in the rotating frame and spin-pin relaxation time in the laboratory frame, which gives insight into the molecular dynamics of the nanostructured systems [5] [6] [7]. The spin-lattice relaxation time in the laboratory frame promotes evaluation of the samples in the $\mathrm{MHz}$ scale. The spin-lattice relaxation time in the rotating frame is sensitive to the movements in the tens of $\mathrm{kHz}$ and the spin-spin relaxation time in the laboratory frame comes from the loss of phase coherence among nuclei in the $x y$ plane, which affects the relaxation of the component perpendicular to the main magnetic field (Bo). The spin-lattice relaxation parameters involve changes in thermal equilibrium of spin systems and the responses of them are intrinsically related to the system's molecular dynamics that is derived from the morphology of the system [5] [6] [7].

Hence, the relaxation parameters are a good tool to understand the changes in the molecular interaction, the molecular dynamics of the hybrid components, the molecular domains in an organic material, the chain organization after the nanoparticles are incorporated into the polymer systems, and the dispersion of the nanoparticles in the polymer matrix. Normally, when spherical nanoparticles such as: titanium dioxide and silica are well dispersed and distributed in the polymer matrix, the proton-spin lattice relaxation times increases because of the rigid behavior of these particles in the polymer matrix [2] [8].

In the past decades, titanium dioxide nanoparticles $\left(\mathrm{TiO}_{2}\right)$ have received a fair amount of attention because of its good thermal stability, accessibility and catalytic properties. It is generally used for various applications, such as paints, 
coatings, plastics, papers, inks, medicines, pharmaceuticals, food products, cosmetics, implants, toothpastes and solar energy conversion, photocatalysis, UV detection, ultrasonic sensing and as a promising material in applications such as water or wastewater treatment. Its environmental compatibility, non toxicity and low price are some of its advantages [9] [10].

Polycaprolactone (PCL) is a linear semi crystalline aliphatic polyester $(\sim 50 \%$ crystallinity), considered as a biocompatible, and bioresorbable material. Its potential use is currently being examined as biodegradable packaging materials, controlled drug release carriers and other medical applications, such as suture filaments. Moreover PCL is approved by Food and Drug Administration (FDA) for biomedical applications. The PCL has a low glass-transition temperature of $-60^{\circ} \mathrm{C}$, a melting point of $60^{\circ} \mathrm{C}$, and exhibits high decomposition temperature around $350^{\circ} \mathrm{C}$. In comparison to other biodegradable polyesters, an in vivo degradation of PCL is considerably long. Another important fact is that the addition of nanofillers such as hydroxyapatite, clays, titanium oxide, graphite and silica does not affect the bioactivity of PCL. However, its low melting temperature, modulus, abrasion resistance, and its relatively high cost are the major disadvantages [11] [12].

Most of the works that developed $\mathrm{PCL} / \mathrm{TiO}_{2}$ nanocomposites used the sol-gel process in situ or melt mixing. The sol gel process allows obtaining the polymer chains into an inorganic network and it involves a series of reactions of hydrolysis and polycondensation from the precursor to the inorganic domain. However, there are some drawbacks of this method, such as: high cost of precursors, residual porosity and shrinkage of a wet gel upon drying [13]. The melt mixing process is a solvent free technique that utilizes heat and pressure to disperse the polymer and nanoparticle. Although, there are some limitations, as the cost of equipment, both of the components must be in the molten state and the large difference in the melt viscosity of the components difficult the $\operatorname{mix}[14]$.

In this context, the present study had two main objectives the first one was to prepare $\mathrm{PCL} / \mathrm{TiO}_{2}$ hybrids through the cast solution method, to produce a good system at the molecular level. The polymer and nanoparticles were solubilized in a solvent and applied on a glass plate using casting device ${ }^{14}$. The other objective was to use nuclear magnetic resonance relaxometry (NMR-relaxometry) to evaluate the molecular dynamic of the samples and to understand the behavior of the new material.

\section{Materials}

Polycaprolactone (PCL) pellets (Mw: 80,000 - 100,000 g/mol), obtained from Sigma Aldrich, was used as the polymer matrix. Titanium dioxide particles $\left(\mathrm{TiO}_{2}\right)$ were supplied by DuPont (Brazil), having specific surface area of $50 \mathrm{mg}^{2} / \mathrm{g}$ and average primary particle size of $25 \mathrm{~nm}$. Chloroform was purchased from Tedia Brazil. 


\subsection{Preparation of Hybrids}

The PCL film was produced using a solvent casting technique. Briefly, the PCL granules were dissolved in chloroform at room temperature overnight with vigorous stirring to obtain a concentration of $5 \% \mathrm{w} / \mathrm{v}$. The solution was poured into a glass Petri dish, which was covered and placed at room temperature for slow evaporation. The dried film was collected and vacuum dried for $48 \mathrm{~h}$. Chloroform was chosen as solvent according to the PCL solubility parameter, obtained in a previous study. Solvent elimination was confirmed by disappearance of chloroform bands at $3034 \mathrm{~cm}^{-1}, 1220 \mathrm{~cm}^{-1}, 774 \mathrm{~cm}^{-1}$ and $680 \mathrm{~cm}^{-1}$ using infrared spectroscopy.

The PCL/titanium dioxide hybrids were also prepared through the solvent casting technique, using chloroform as the solvent. The solutions of PCL and titanium dioxide were stirred separately at room temperature for 24 hours to prepare the nanomaterials with different titanium dioxide ratios, ranging from $0.05 \%$ $\mathrm{w} / \mathrm{w}$ to $0.35 \% \mathrm{w} / \mathrm{w}$ in relation to PCL concentration. The titanium dioxide dispersions were subjected to ultrasound for one hour. The flasks with the isolated solutions were sealed with glass cover and stirred at room temperature for $24 \mathrm{~h}$. After that, the solutions were mixed and left for $24 \mathrm{~h}$ under stirring. The resulting mixture was poured into Petri dishes and kept at room temperature. The hybrids films were further dried under vacuum for $48 \mathrm{~h}$ and all the samples were stored in desiccators until use [6] [15].

\subsection{Characterization Techniques}

\subsubsection{FTIR Analysis}

The infrared spectra were recorded with a Nicolet, Magna FR 760, Fourier transform infrared (FTIR) spectrometer capable of both mid-infrared (mid-IR) and far-infrared (far-IR) measurements, was used to spectroscopically examine inorganic filler, polymer and hybrids. An integral Diamond Attenuated Total Reflectance (ATR) accessory was used for all measurements. Far-IR Attenuated Total Reflection (ATR) measurements were made using a built-in Diamond ATR accessory, solid substrate beamsplitter and standard IR source. Mid-IR ATR measurements were made using a built-in Diamond ATR accessory, potassium bromide $(\mathrm{KBr})$ beamsplitter and standard IR source. All spectra were obtained using 64 scans at $4 \mathrm{~cm}^{-1}$ resolution; total analysis time was three minutes per sample. The data were collected and processed using Thermo Scientific ${ }^{\mathrm{m}}$ OMNIC ${ }^{\mathrm{m}}$ software. For the $\mathrm{TiO}_{2}$ and PCL enough powder was placed onto the Diamond surface to cover it ( 1 to 3 miligrams) and the pressure device used to force the sample into contact with the Diamond crystal. The hybrids films were placed over the Diamond surface and pressure applied in the same manner as the powder samples.

\subsubsection{X-Ray Diffraction}

The crystalline structure of the PCL and $\mathrm{PCL} / \mathrm{TiO}_{2}$ hybrids were investigated by $\mathrm{X}$-ray diffraction (XRD) using a Rigaku D/Max 2400 diffractometer, with nick- 
el-filtered $\mathrm{CuK} \alpha$ radiation of wavelength $1.54 \AA$, at room temperature. The $2 \theta$ scanning ranged from $2^{\circ}$ to $70^{\circ}$, with $0.02^{\circ}$ steps, operated at $40 \mathrm{KV}$ and $30 \mathrm{~mA}$. The degree of crystallinity of the samples was calculated from the integrated area of X-ray diffraction data, using the Ftk software, for which were assumed Gaussian profiles for crystalline and amorphous peaks. Linear background correction was applied separately to the observed peaks before obtain the area under each peak. The areas under the crystalline and amorphous phase were determined in arbitrary units and the degree of crystallinity $\left(\mathrm{X}_{c}\right)$ was obtained using the following relationship (Equation (1)) [2] [6] [15].

$$
X_{c}=\frac{I_{c}}{I_{a}+I_{c}}
$$

where $I_{a}$ and $I_{c}$ are the integrated intensities corresponding to the crystalline and amorphous phases.

\subsubsection{NMR Relaxation Measurements}

All measurements of spin-lattice relaxation times $\left(\mathrm{T}_{1} \mathrm{H}\right.$ and $\left.\mathrm{T}_{1} \rho \mathrm{H}\right)$ were performed using a low-field NMR spectrometer, Resonance Maran Ultra 23, operating at $23.4 \mathrm{MHz}$ (for protons) and equipped with an $18 \mathrm{~mm}$ variable temperature probe. The pulse sequence used for $\mathrm{T}_{1} \mathrm{H}$ determination was an inversion-recovery (recycle delay $180^{\circ}-\tau$ - $90^{\circ}$ acquisition). The $90^{\circ}$ pulse, $4.6 \mu \mathrm{s}$, was calibrated automatically by the instrument's software. The amplitude of the FID was sampled for twenty $\tau$ data points, ranging from 0.1 to $5000 \mathrm{~ms}$, with four scans each and $5 \mathrm{~s}$ of recycle delay. The equipment's precision is $\pm 2 \%$. The relaxation values were calculated employing the following equation (Equation (2)). The temperature of the analysis was $25^{\circ} \mathrm{C}$. The $T_{1} H$ values and relative intensities were obtained by fitting the exponential data with the aid of the program WINFIT. Distributed exponential fittings as a plot of relaxation amplitude versus relaxation time were performed by using the WINDXP software [5] [15].

$$
M o=M z\left(1-\exp ^{-t / T_{1}}\right)
$$

where, Mo is an equilibrium value, $M z$ is a time period during which spin-lattice relaxation occurs causing $M z$ to go from value of $-M o$ through zero to its equilibrium value of $M o, \tau$ is time period delay and $T_{1}$ is a spin-lattice relaxation time [5] [15].

The $\mathrm{T}_{1} \rho \mathrm{H}$ values were measured with ordinary spin-lock pulse sequencing, with was $90^{\circ} \mathrm{x}$-(pin-lock pulse) $\mathrm{y}$-(acquisition). The amplitude of the FID was sampled for $32 \tau$ data points, ranging from 25 to $100,000 \mu$ s, with four scans each and $5 \mathrm{~s}$ of recycle delay. The $\mathrm{T}_{1} \rho \mathrm{H}$ values and relative intensities were obtained also by fitting the exponential data with the aid of the WINFIT program and the distributed exponential fitting of plots of relaxation amplitude versus relaxation time was performed by using the WINDXP software. The spin-lock field was $12.5 \mathrm{kHz}$ [2] [16].

The Equation (3) is used to calculate the $\mathrm{T}_{1} \rho \mathrm{H}$ values: 


$$
y=y_{0}+A_{i e}^{-(x-x o) / t_{1}}
$$

where, $y$ is the total magnetization intensity; $Y_{0}$ is the intensity of the magnetization at the initial time; $A_{i}$ is the time constant; $X$ is the signal weight at the initial point; $X_{0}$ is the signal weight at the initial time and $t_{1}$ is time interval between $180^{\circ}$ and $90^{\circ}$ pulses [5].

\subsubsection{Thermal Analysis}

The thermal properties of PCL and its hybrids were investigated using a Rigaku TAS 100 differential scanning calorimeter. Dry nitrogen gas with a flow rate of $20 \mathrm{ml} / \mathrm{min}$ was purged through the cell during all measurements and thermal treatments, the instrument having been calibrated with an indium standard. The thermograms were recorded between $-70^{\circ} \mathrm{C}$ and $150^{\circ} \mathrm{C}$, with heating rate of 10 ${ }^{\circ} \mathrm{C} / \mathrm{min}^{-1}$. The analysis involved the first heating from $-70^{\circ} \mathrm{C}$ and $150^{\circ} \mathrm{C}$ followed by fast cooling $\left(100{ }^{\circ} \mathrm{C} / \mathrm{min}^{-1}\right)$, followed by another heating cycle of $10^{\circ} \mathrm{C} / \mathrm{min}^{-1}$, from $-70^{\circ} \mathrm{C}$ and $150^{\circ} \mathrm{C}$. The fraction $X_{c} \%$ of material crystallized after an interval $t$ was evaluated by the ratio of the crystallization area at the time, $t$, over the total area, according to the Equation (4), and the crystallinity degrees $\left(X_{c}\right)$ were determined by measuring the enthalpy of fusion of the PCL in the crystalline state, using the literature data of $139.6 \mathrm{Jg}^{-1}$ [2] [16]:

$$
X_{c}=\frac{\Delta H_{f}}{\Delta H_{100 \%}} \times 100
$$

The Thermogravimetric analysis (TGA) was carried out on TA instruments Q500 (USA) apparatus from $25^{\circ} \mathrm{C}$ to $500^{\circ} \mathrm{C}$ under nitrogen flow $(50 \mathrm{~mL} / \mathrm{min}$ ) at $10{ }^{\circ} \mathrm{C} / \mathrm{min}$ heating rates [2] [16].

\section{Results and Discussion}

\subsection{Hybrids' Structural Characterization}

The chemical structure of the $\mathrm{PCL} / \mathrm{TiO}_{2}$ hybrids can be identified by FTIR. Consequently, this technique is widely used to establish the formation of new materials. In addition, an infrared analysis in the distant region is useful for inorganic studies since the stretching vibrations and angular deformation between organic/inorganic compounds occurs at frequencies lower than $650 \mathrm{~cm}^{-1}$ [17].

The FTIR spectra of the PCL/TiO $\mathrm{T}_{2}$ hybrids are shown in Figure 1 and Figure 2. In Figure 1, the two narrows signals located at $2870 \mathrm{~cm}^{-1}$ and $2954 \mathrm{~cm}^{-1}$ are attributed to C-H stretching vibrations of the PCL's hydrocarbon and the narrow peak centered at $1734 \mathrm{~cm}^{-1}$ is derived from the stretching vibration of the PCL's carbonyl groups $(\mathrm{C}=\mathrm{O})$ [18]. The peaks around of $850 \mathrm{~cm}^{-1}$ and $1125 \mathrm{~cm}^{-1}$ correspond to the $\mathrm{Ti}-\mathrm{O}-\mathrm{Ti}$ and $\mathrm{Ti}-\mathrm{O}-\mathrm{C}$ stretching, respectively [19] [20].

The FTIR spectra of the hybrids formed by PCL and $\mathrm{TiO}_{2}$ (Figure 2) presented the characteristic signals of $\mathrm{TiO}_{2}$ in the far infrared region at $600 \mathrm{~cm}^{-1}$ and $100 \mathrm{~cm}^{-1}$. The broadband over the range of $400-700 \mathrm{~cm}^{-1}$ is related to bending and stretching mode of Ti-O-Ti, and the signals at $450 \mathrm{~cm}^{-1}$ and 620 $\mathrm{cm}^{-1}$ are due to the Ti-O-Ti bond of rutile spectrum [21] [22]. Besides that, the 


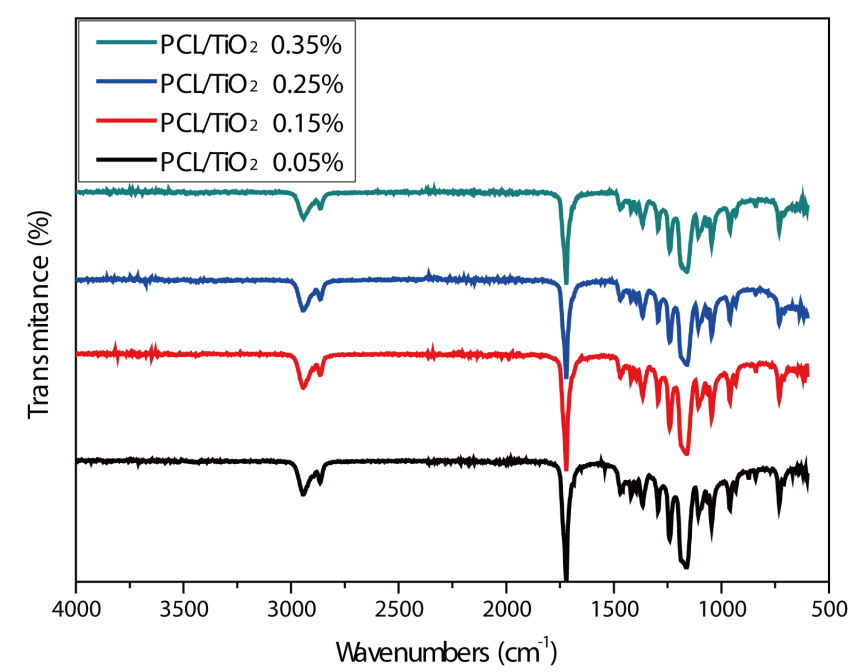

Figure 1. The FTIR spectra of $\mathrm{PCL} / \mathrm{TiO}_{2}$ hybrids, in the mid region.

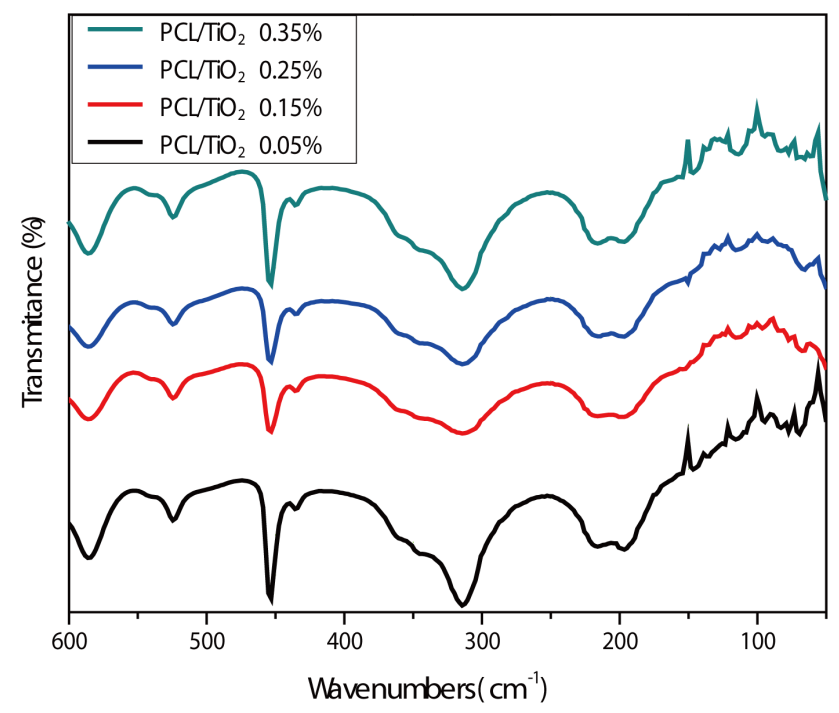

Figure 2. The far FTIR spectra of $\mathrm{PCL} / \mathrm{TiO}_{2}$ hybrids.

FTIR in the far region is able to distinguish the titanium dioxide anatase from titanium dioxide rutile. The titanium dioxide anatase shows peaks at $630 \mathrm{~cm}^{-1}$, $510 \mathrm{~cm}^{-1}$ and $140 \mathrm{~cm}^{-1}$ and the titanium dioxide rutile presents peaks at $600 \mathrm{~cm}^{-1}$ and $450 \mathrm{~cm}^{-1}$ [23]. The FTIR analysis confirmed the presence of titanium dioxide rutile in the samples.

Moreover, in hybrids systems the broader bands in the region of $450 \mathrm{~cm}^{-1}$ and $915 \mathrm{~cm}^{-1}$ can be related to the $\mathrm{TiO}_{2}$ vibrations, indicating that there was an interaction between the PCL chains and the nanoparticles [18].

\subsection{XRD Analysis}

The hybrid materials were submitted to wide-angle X-ray diffraction measurement and the XRD curves are shown in Figure 3. The XRD technique is based on the elastic scattering of X-rays from structures that have long-range order. It 


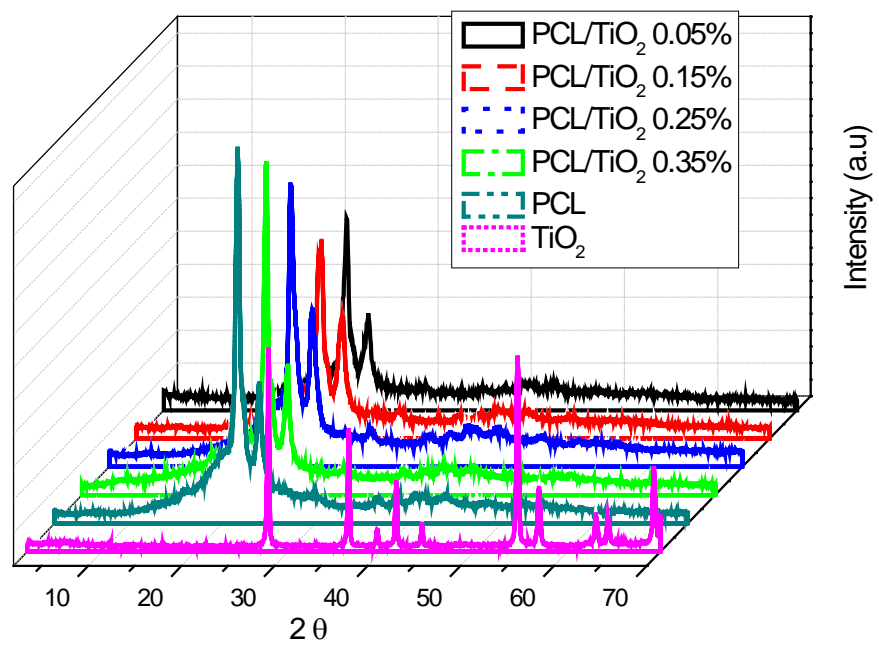

Figure 3. XRD curves of $\mathrm{TiO}_{2}$ and $\mathrm{PCL} / \mathrm{TiO}_{2}$ hybrids.

is an efficient analytical technique to identify and characterize crystalline materials. The spectra of $\mathrm{TiO}_{2}$ exhibited sharp signals, indicating its crystalline nature. Sharp signals signify good crystallinity of nanoparticles [24] [25]. The X-ray diffraction showed that the $\mathrm{TiO}_{2}$ nanoparticles were a mixture of anatase and rutile form. The $\mathrm{TiO}_{2}$ nanoparticles in the anatase form presented diffractions peaks at $36^{\circ}, 54^{\circ}$ and $57^{\circ}$, while the $\mathrm{TiO}_{2}$ in the rutile form presented peaks at $29^{\circ}, 42^{\circ}$ and $45^{\circ}$ [26].

Figure 3 also shows the diffratograms for $\mathrm{PCL} / \mathrm{TiO}_{2}$ hybrids. The strong and sharp signals located at $21.3^{\circ}$ and $23.8^{\circ}$ are attributed to the [110] and [200] crystallographic planes of the PCL orthorhombic crystal, respectively [6] [15] [16]. From the X-ray diffraction spectra, it was observed that the incorporation of $\mathrm{TiO}_{2}$ nanoparticles did not affect the crystalline structure of PCL because its strong and sharp signals were maintained after the $\mathrm{TiO}_{2}$ introduction. These results are in agreement with the work of Nandagopal et al. (2016) [27], where it was also observed that a higher concentration of titanium dioxide nanoparticles reduced the PCL crystallinity.

The $\mathrm{PCL} / \mathrm{TiO}_{2}$ hybrids containing $0.25 \%$ and $0.35 \% \mathrm{w} / \mathrm{w}$ of $\mathrm{TiO}_{2}$ showed an increase in the intensity of the diffraction peaks related to PCL when compared to hybrids containing $0.05 \%$ and $0.15 \% \mathrm{w} / \mathrm{w}$ of $\mathrm{TiO}_{2}$. Consequently, the increase in $\mathrm{TiO}_{2}$ concentration may have modified the PCL crystallization pattern [18] [28]. Nevertheless, nonappearance of any new peak in the plots for the hybrids shows that no new phase was formed during the process of synthesis.

The crystallinity degree of all hybrids developed was obtained by curve fitting to calculate the area of each peak. Linear background correction was applied separately to the observed peaks before obtain the area under each peak, for which it was assumed a Gaussian profile. The crystalline values for PCL and $\mathrm{PCL} / \mathrm{TiO}_{2}$ hybrids are shown in Table 1.

Table 1 shows that the incorporation of $\mathrm{TiO}_{2}$ nanoparticles decreased the PCL crystallinity in all hybrid systems, compared to pure PCL. The concentration of 
Table 1. Crystalline values for PCL and $\mathrm{PCL} / \mathrm{TiO}_{2}$ hybrids.

\begin{tabular}{cc}
\hline Sample & $\boldsymbol{X}_{\mathrm{c}}(\%)$ \\
\hline $\mathrm{PCL}$ & 56.78 \\
$\mathrm{PCL} / \mathrm{TiO}_{2} 0.05 \%$ & 42.38 \\
$\mathrm{PCL} / \mathrm{TiO}_{2} 0.15 \%$ & 43.42 \\
$\mathrm{PCL} / \mathrm{TiO}_{2} 0.25 \%$ & 41.72 \\
$\mathrm{PCL} / \mathrm{TiO}_{2} 0.35 \%$ & 41.06 \\
\hline
\end{tabular}

$0.35 \%$ of $\mathrm{TiO}_{2}$ showed a major reduction in the PCL crystallinity. Probably, the $\mathrm{TiO}_{2}$ nanoparticles hindered the PCL crystallization, leading to some changes in the semi-crystalline PCL structure, resulting in a less ordered compound.

\subsection{NMR Measurements}

As mentioned before, the NMR relaxometry can be used to study the molecular dynamics of the new systems. The proton relaxation times are very sensible to molecular motions, in different frequency ranges. The spin lattice relaxation time, in the laboratory frame, $\mathrm{T}_{1} \mathrm{H}$, detects the fast molecular motions, in the $\mathrm{MHz}$ scale, and the domains between 25 to $50 \mathrm{~nm}$. The spin lattice relaxation time, in the rotating frame, $T_{1 \rho}$, detects the slow molecular motions, in the $\mathrm{kHz}$ scale, between 10 to $50 \mathrm{kHz}$ and shows that the material is homogenous in the range of 4 to $25 \mathrm{~nm}$ [5] [6] [7].

So, the $\mathrm{T}_{1} \mathrm{H}$ provides information's on the presence of different mobility domains, homogeneity, miscibility, interaction among the components. Since a higher value of proton spin lattice relaxation time, $\mathrm{T}_{1} \mathrm{H}$, represents a more restrict environment, with less molecular motions. While a lower value of proton spin lattice relaxation time, $\mathrm{T}_{1} \mathrm{H}$, represents a more flexible environment, with more molecular motions [4] [5] [7]. The spin lattice relaxation time in the rotating frame, $T_{1 \rho}$, provides information's about the segmental motions and the slow molecular motions of the polymer chains. This parameter also allows observing the homogeneity of the polymer systems, since it is sensitive to the spatial proximity of the polymer chains [2] [5].

According to Table 2 and Figure 4 the neat PCL presented two domains with different $\mathrm{T}_{1} \mathrm{H}$ values. The first domain presented $\mathrm{T}_{1} \mathrm{H}$ value around $30 \mathrm{~ms}$ and it is correlated to the more mobile region of PCL (amorphous region). The second domain presented values around $142 \mathrm{~ms}$ and it is related to the less mobile region of PCL (crystalline region) [6] [15]. Generally the semi-crystalline polymers, such as PCL, present at least two types of molecular organization: the amorphous phase, where the protons presented less relaxation time values since it has more mobility; and the crystalline phase, where the protons presented higher relaxation time values because it has less molecular mobility [2] [16].

In Table 2, the PCL/ $\mathrm{TiO}_{2}$ hybrids systems showed a higher $\mathrm{T}_{1} \mathrm{H}$ values than the neat PCL, indicating that the addition of $\mathrm{TiO}_{2}$ nanoparticle's promoted the 


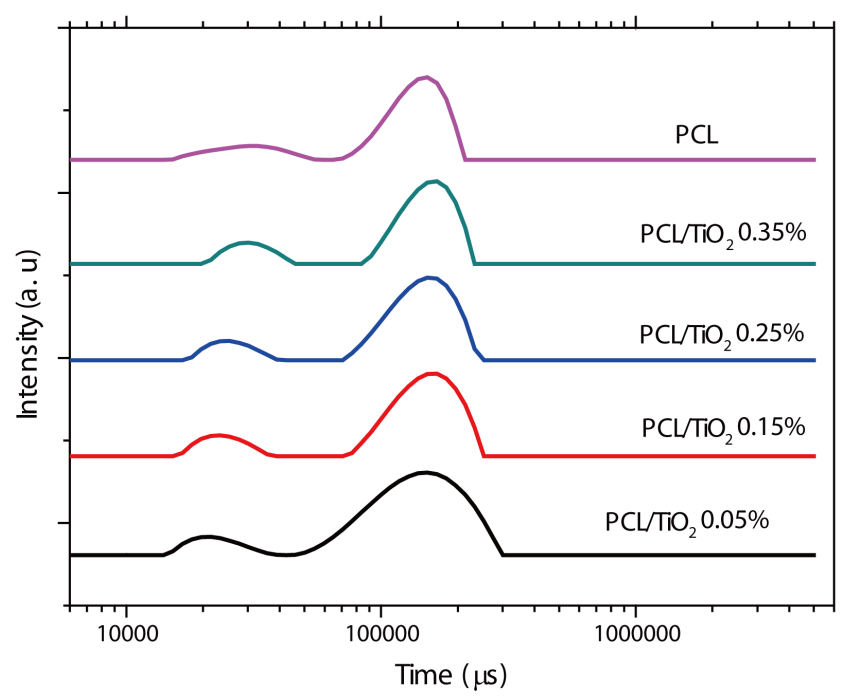

Figure 4. Distribution curves obtained by low field NMR for PCL and $\mathrm{PCL} / \mathrm{TiO}_{2}$ hybrids.

Table 2. Proton spin-lattice relaxation times of PCL and $\mathrm{PCL} / \mathrm{TiO}_{2}$ hybrids determined by low field NMR, with $2 \%$ error.

\begin{tabular}{|c|c|c|c|}
\hline Sample & $\begin{array}{c}\mathrm{T}_{1} \mathrm{H}_{1 \operatorname{mxp}} \\
(\mathrm{ms})( \pm 2 \%)\end{array}$ & $\begin{array}{c}\mathrm{T}_{1} \mathrm{H}_{2 \mathrm{Exp}} \\
\text { (ms) }( \pm 2 \%)\end{array}$ & $\begin{array}{c}\mathrm{T}_{1} \rho \mathrm{H} \\
(\mathrm{ms})( \pm 2 \%)\end{array}$ \\
\hline PCL & 106 & $\begin{array}{c}30 \\
142\end{array}$ & 6.7 \\
\hline $\mathrm{PCL} / \mathrm{TiO}_{2}$ 0.05\% & 115 & $\begin{array}{c}31 \\
154\end{array}$ & 7.5 \\
\hline PCL/TiO2 0.15\% & 116 & $\begin{array}{c}26 \\
154\end{array}$ & 7.9 \\
\hline $\mathrm{PCL} / \mathrm{TiO}_{2} 0.25 \%$ & 118 & $\begin{array}{c}33 \\
165\end{array}$ & 7.6 \\
\hline $\mathrm{PCL} / \mathrm{TiO}_{2}$ 0.35\% & 115 & $\begin{array}{c}27 \\
149\end{array}$ & 7.6 \\
\hline
\end{tabular}

formation of a new material with less molecular mobility of the polymer chains due to the formation of newer and strong interactions between the $\mathrm{TiO}_{2}$ nanoparticles and the PCL chains, increasing its rigidity. This may occur because of the formation of the new molecular rearrangement of the PCL chains.

In addition, the increase of $\mathrm{TiO}_{2}$ concentration did not show a significant difference in the $\mathrm{T}_{1} \mathrm{H}$ value, suggesting that there was no change in the molecular dynamics, up to $0.25 \%$ concentration of $\mathrm{TiO}_{2}$ nanoparticles. However, with $0.35 \%$ of $\mathrm{TiO}_{2}$ nanoparticles in the PCL matrix there was a slight reduction in $\mathrm{T}_{1} \mathrm{H}$ value and it can indicate a phase separation. Since a higher concentration of $\mathrm{TiO}_{2}$ nanoparticles may hinder its dispersion in the polymer matrix and did not change the PCL molecular mobility.

Figure 4 shows the domain distribution curves of proton spin-lattice relaxation times obtained for PCL and $\mathrm{PCL} / \mathrm{TiO}_{2}$ hybrids. All samples presented two well defined domains, related to the domains of PCL, as described above. Con- 
sequently, the two regions maintained its molecular dynamics. The Bi-exponential analysis of the spin lattice relaxation time was used because there was a significant correlation between the measured of NMR constant $\left(\mathrm{T}_{1} \mathrm{H}\right)$ and the domain curve, confirming that the samples have two domains, when analyzed in a spectrometer operating at $23.4 \mathrm{MHz}$.

The second domain of all samples presented higher $\mathrm{T}_{1} \mathrm{H}$ values than the neat PCL, indicating that there was an increase in the PCL rigidity, in the crystalline phase, with the introduction of $\mathrm{TiO}_{2}$. However, these results are not in accordance with the results obtained by the XRD analysis. Since a decrease in the crystallinity degree of the samples should decrease de $\mathrm{T}_{1} \mathrm{H}$ values of the second domains. Besides that, the DSC analysis indicated the opposite behavior, showing higher crystallinity values with the increase of $\mathrm{TiO}_{2}$ concentration. Nevertheless, the DSC values are greater than those determined from XRD profiles, since part of the material in amorphous state at room temperature is able to crystallize during the heating process and contribute to the final degree of ordering [3].

In our previous studies using the fast field cycling NMR relaxometry, the PCL hybrids presented three distinct environments: crystallites, rigid amorphous and flexible-amorphous regions, with three distinct spin-lattice relaxation times, $\mathrm{T}_{11}$, $\mathrm{T}_{12}, \mathrm{~T}_{13}$. The dispersion of $\mathrm{TiO}_{2}$ nanoparticles in the PCL matrix affected with greater intensity the protons mobility in the rigid amorphous region. The rigid amorphous region represents the slower PCL chain modes [6].

In the system with $0.05 \%$ of $\mathrm{TiO}_{2}$ there was a great interaction with PCL since the two domains presented a peak base wider than the PCL peak base.

Table 2 and Figure 5 show the $\mathrm{T}_{1} \rho \mathrm{H}$ values and the $\mathrm{T}_{1} \rho \mathrm{H}$ decay for PCL and all samples, respectively. The $\mathrm{T}_{1} \rho \mathrm{H}$ curves show the same pattern and their fits gave a higher value of this parameter. The $\mathrm{T}_{1} \rho \mathrm{H}$ values increased for all systems, compared to pure PCL. Thus, the molecular motions of PCL chains became more restricted and promoted a reorientation of PCL chains, in the 4 to $25 \mathrm{~nm}$ scale, with $\mathrm{TiO}_{2}$ introduction. The $\mathrm{T}_{1} \rho \mathrm{H}$ data confirmed the $\mathrm{T}_{1} \mathrm{H}$ results, indicating that the $\mathrm{TiO}_{2}$ nanoparticles restricted the PCL mobility.

\subsection{Thermal Degradation}

Thermogravimetric analysis is commonly used to identify the maximum temperature supported by a material, and it is characterized through mass loss due to volatilization with increasing temperature. The thermal stability of PCL and $\mathrm{PCL} / \mathrm{TiO}_{2}$ hybrids materials were studied by analyzing the TGA curves. Figure 6 show the mass loss (TG\%) curves of PCL and $\mathrm{PCL} / \mathrm{TiO}_{2}$ hybrids.

For PCL, the initial degradation temperature was $383^{\circ} \mathrm{C}$, as can be seen in Table 3. The addition of $\mathrm{TiO}_{2}$ nanoparticles decreased the initial degradation temperature and the maximum temperature degradation when compared to the neat PCL. Therefore, the $\mathrm{TiO}_{2}$ nanoparticles decreased the PCL thermal resistance. However, it can be considered that the systems containing different concentrations of $\mathrm{TiO}_{2}$ presented a good thermostability, since no mass loss occurred before $370^{\circ} \mathrm{C}$. 


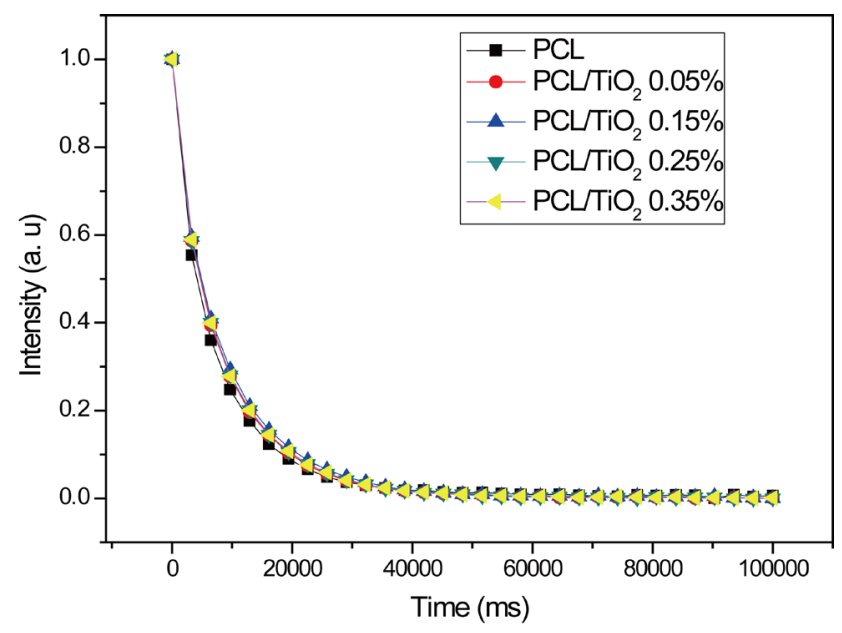

Figure 5. $\mathrm{T}_{1} \rho \mathrm{H}$ decay for PCL and $\mathrm{PCL} / \mathrm{TiO}_{2}$ hybrids.

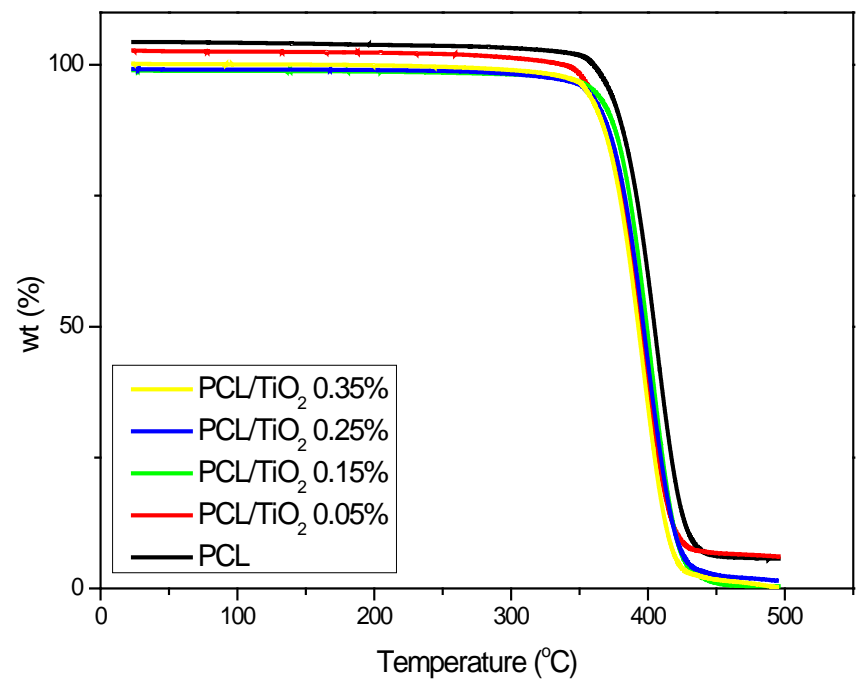

Figure 6. Mass loss (TG\%) curves for PCL and PCL/TiO 2 hybrids.

Table 3. Temperature onset of degradation $\left(\mathrm{T}_{\text {onset }}\right)$ and the maximum temperature $\left(\mathrm{T}_{\max }\right)$ of PCL and $\mathrm{PCL} / \mathrm{TiO}_{2}$ hybrids.

\begin{tabular}{ccc}
\hline Samples & $\mathrm{T}_{\text {onset }}\left({ }^{\circ} \mathrm{C}\right)$ & $\mathrm{T}_{\text {Max }}\left({ }^{\circ} \mathrm{C}\right)$ \\
\hline $\mathrm{PCL}$ & 383 & 409 \\
$\mathrm{PCL} / \mathrm{TiO}_{2} 0.05 \%$ & 370 & 397 \\
$\mathrm{PCL} / \mathrm{TiO}_{2} 0.15 \%$ & 376 & 400 \\
$\mathrm{PCL} / \mathrm{TiO}_{2} 0.25 \%$ & 375 & 400 \\
$\mathrm{PCL} / \mathrm{TiO}_{2} 0.35 \%$ & 372 & 397
\end{tabular}

Figure 6 shows the results related to the thermal stability of the $\mathrm{PCL} / \mathrm{TiO}_{2}$ hybrids. Looking at the curves achieved under a nitrogen atmosphere, it can be said that the degradability was almost not affected by the incorporation of $\mathrm{TiO}_{2}$ nanoparticles. Moreover, the decomposition seems to occur in a unique stage. 
Only, the onset temperature of decomposition was slightly moved to a lower temperature. In addition, the presence of $\mathrm{TiO}_{2}$ nanoparticles slightly favored the degradability and the temperature of maximum degradation was shifted towards lower values than the neat PCL.

Addition of $\mathrm{TiO}_{2}$ has displayed different effects depending on the polymeric matrix in which it is incorporated: a considerable catalytic effect in nanocomposites based in ethylene-vinyl alcohol (EVOH) copolymer or an almost null action in polypropylene. Muñoz-Bonilla et al. (2013) also verified that the presence of $\mathrm{TiO}_{2}$ nanoparticles slightly favored the degradability of the PCL matrix ${ }^{3}$.

\subsection{Differential Scanning Calorimetry}

The melting temperatures $(\mathrm{Tm})$ of the first and second heating, and transition enthalpy $(\triangle \mathrm{H})$ of the first and second heating of PCL and PCL/TiO ${ }_{2}$ hybrids were investigated by DSC. Figure 7 shows the DSC curves for PCL and $\mathrm{PCL} / \mathrm{TiO}_{2}$ hybrids. Table 4 shows the enthalpy values and the melting and crystallization temperatures ( $\Delta \mathrm{Hf}, \Delta \mathrm{Hc} ; T_{m}$ and $T_{c}$ ), as well as the degree of crystallinity $\left(X_{c} \%\right)$. The glass transition temperature has not been described because the objective of the DSC analysis was to verify the influence of titanium dioxide nanoparticles in the crystallization process.

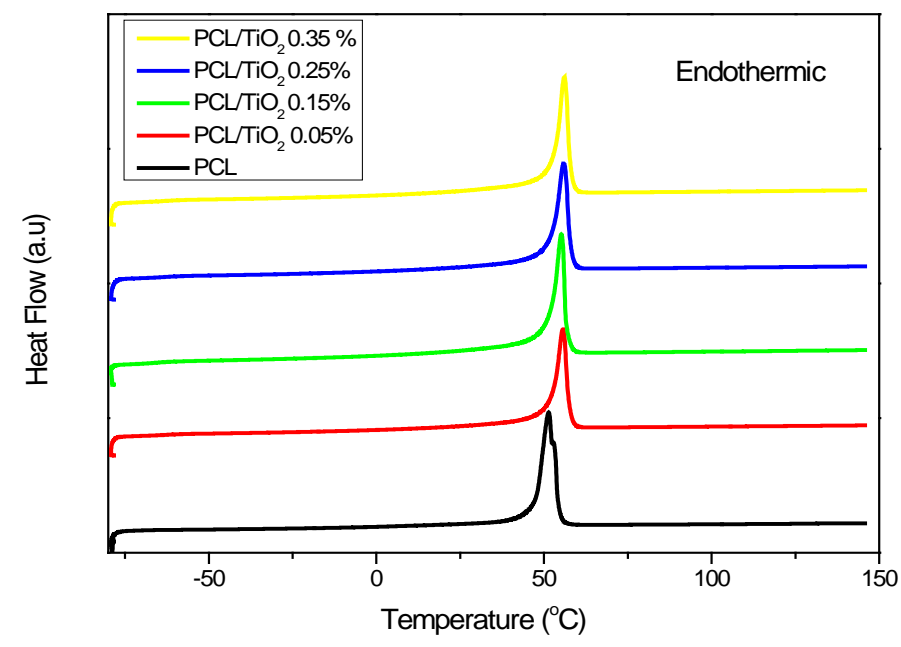

Figure 7. DSC curves of $\mathrm{PCL}$ and $\mathrm{PCL} / \mathrm{TiO}_{2}$ hybrids, second heating.

Table 4. Transition temperatures and enthalpies obtained in the second and third heating cycles (DSC) of PCL and PCL/TiO 2 hybrids.

\begin{tabular}{cccccc}
\hline Samples & $T_{c}\left({ }^{\circ} \mathrm{C}\right)$ & $\Delta H_{c}(\mathrm{~J} / \mathrm{g})$ & $T_{m}\left({ }^{\circ} \mathrm{C}\right)$ & $\Delta H_{m}(\mathrm{~J} / \mathrm{g})$ & $X_{c} \%$ \\
\hline $\mathrm{PCL}$ & 32.0 & 71.1 & 53.0 & 73.4 & 52.7 \\
$\mathrm{PCL} / \mathrm{TiO}_{2} 0.05 \%$ & 24.5 & 51.0 & 55.3 & 54.2 & 38.8 \\
$\mathrm{PCL} / \mathrm{TiO}_{2} 0.15 \%$ & 26.3 & 72.9 & 55.2 & 72.8 & 52.1 \\
$\mathrm{PCL} / \mathrm{TiO}_{2} 0.25 \%$ & 23.0 & 59.8 & 55.8 & 63.8 & 45.0 \\
$\mathrm{PCL}_{\mathrm{TiO}} 20.35 \%$ & 33.4 & 60.3 & 55.9 & 67.6 & 48.4 \\
\hline
\end{tabular}


The pure PCL showed a $\Delta H_{c}$ of $71 \mathrm{~J} / \mathrm{g}$ while $\mathrm{PCL} / \mathrm{TiO}_{2} 0.05 \%$ hybrids showed a $\Delta H_{c}$ of $51 \mathrm{~J} / \mathrm{g}$, indicating a reduction in the enthalpy value of crystallization. The addition of $0.05 \%$, hindered the crystallization process by drastically lowering the related enthalpy of crystallization. This system also showed a decrease in the $\Delta H_{m}$, which could be related to a restriction in the PCL crystallization kinetics. Probably the multiple interactions formed in the organic-inorganic hybrids, using $0.05 \%$ of titanium dioxide, caused a highly restricted segmental motion, hindering crystallization [2].

However, the hybrids of PCL with $0.15 \%$ of $\mathrm{TiO}_{2}$ nanoparticles showed a $\Delta \mathrm{Hc}$ of $73 \mathrm{~J} / \mathrm{g}$, indicating that this nanoparticles concentration increased the enthalpy value of crystallization.

The $\mathrm{PCL} / \mathrm{TiO}_{2}$ hybrids presented a reduction in the crystallization temperature, in the enthalpy of crystallization and in the melting enthalpy, except for the system with $0.15 \% \mathrm{w} / \mathrm{w}$ of $\mathrm{TiO}_{2}$ nanoparticles, compared to the neat PCL. So, the $\mathrm{TiO}_{2}$ nanoparticles interfered in the crystallization process. The melting temperatures of the hybrids systems were higher than the neat PCL. The degree of crystallinity was also lower than the PCL, except for the system containing $0.15 \%$ $\mathrm{w} / \mathrm{w} \mathrm{TiO}_{2}$, indicating that the $\mathrm{TiO}_{2}$ particles restricted the PCL mobility. Consequently, the $0.15 \% \mathrm{w} / \mathrm{w}$ concentration was able to distribute between the PCL chains and act as nucleating agent for the crystallization process, increasing the PCL crystallinity.

Bajsić et al. (2014) also demostrated that the melting point of the PCL/TiO composites was slightly higher with the increase of $\mathrm{TiO}_{2}$ concentration. When the content of $\mathrm{TiO}_{2}$ nanoparticles increased the crystallization temperature of the composites decreased. Only in $\mathrm{PCL} / \mathrm{TiO}_{2}$ composites prepared with $2 \mathrm{wt} \%$ of $\mathrm{TiO}_{2}$ particles the crystallization temperature increased [29]. It was observed the same pattern for the nanocomposite containing $0.35 \%$ of $\mathrm{TiO}_{2}$.

Excluding the results of crystallinity calculated for the PCL sample with $0.15 \%$ of $\mathrm{TiO}_{2}$, the XRD analysis showed a decreasing trend in the crystallinity degree with the increase of $\mathrm{TiO}_{2}$ content, whereas the DSC indicated the opposite behavior, showing an increase in the values of crystallinity with the increase of $\mathrm{TiO}_{2}$ concentration. Nevertheless, the crystallinity values determined by DSC are more accurate than those determined from XRD profiles, since part of the material in amorphous state at room temperature is able to crystallize during the heating process and contribute to the final degree of ordering [3].

\section{Conclusion}

In this study, the $\mathrm{PCL} / \mathrm{TiO}_{2}$ hybrids were successfully prepared by solvent cast technique. It was possible to produce homogenous $\mathrm{PCL} / \mathrm{TiO}_{2}$ hybrids, by solvent cast technique, with nanoparticles effectively dispersed. The FTIR analysis indicated that there was an interaction between the PCL chains and the $\mathrm{TiO}_{2}$ nanoparticles. The XRD analysis showed an increase of the amorphous halo and this can be the result of the interaction of the $\mathrm{TiO}_{2}$ with the PCL chains. The PCL/TiO 
hybrids systems showed a higher $\mathrm{T}_{1} \mathrm{H}$ values than the neat PCL, indicating that the addition of $\mathrm{TiO}_{2}$ nanoparticle's promoted the formation of a new material with less molecular mobility. The $\mathrm{T}_{1} \rho \mathrm{H}$ data confirms the $\mathrm{T}_{1} \mathrm{H}$ results, indicating that the $\mathrm{TiO}_{2}$ nanoparticles restricted the PCL mobility. In the thermal degradation analysis, it is observed that the $\mathrm{TiO}_{2}$ nanoparticles decreased the PCL thermal resistance. In DSC analysis, the $\mathrm{PCL} / \mathrm{TiO}_{2}$ hybrids presented a reduction in the crystallization temperature, in the enthalpy of crystallization, in the melting enthalpy and crystallinity degree, with the exception of $0.15 \% \mathrm{w} / \mathrm{w}$ of $\mathrm{TiO}_{2}$ nanoparticles. These hybrids have a great potential for applications in many fields, especially in the biomedical and pharmaceutical area, since they are formed by biocompatible and biodegradable polymer, PCL, and titanium dioxide nanoparticles, which is used as pharmaceutical excipient.

\section{Acknowledgements}

The authors are grateful to CAPES, CNPQ and FAPERJ for all grants.

\section{References}

[1] Arslan, M., Tasdelen, M.A., Uyar, T. and Yagci, Y. (2015) Poly(epsilon caprolactone)/clay Nanocomposites via Host-Guest Chemistry. European Polymer Journal, 71, 259-267. https://doi.org/10.1016/j.eurpolymj.2015.08.006

[2] Monteiro, M.S.S.B., Neto, R.C., Souza, I.C.S., Silva, E.O. and Tavares, M.I.B. (2012) Inorganic-Organic Hybrids Based on Poly(ع-Caprolactone) and Sílica Oxide and Characterization by Relaxometry Applying Low-Field NMR. Materials Research, 15, 825-832. https://doi.org/10.1590/S1516-14392012005000121

[3] Muñoz-Bonilla, A., Cerrada, M.L., Fernández-García. M., Kubacka, A., Ferrer, M. and Fernández-García, M. (2013) Biodegradable Polycaprolactone-Titania Nanocomposites: Preparation, Characterization and Antimicrobial Properties. International Journal of Molecular Science, 14, 9249-9266.

https://doi.org/10.3390/ijms14059249

[4] Brito, L.M., Sebastião, P.J.O. and Tavares, M.I.B. (2015) NMR Relaxometry Evaluation of Nanostructured Starch-PLA Blends. Polymer Testing, 45, 161-167.

https://doi.org/10.1016/j.polymertesting.2015.06.011

[5] Silva, P.S.R.C., Menezes, L.R. and Tavares, M.I.B. (2016) The Influence of Organo-Clay Ratio in the HIPS-OMMT Nanocomposites Analyzed by Proton Spin-Lattice and Spin-Spin Relaxation Times. Materials Science and Applications, 7, 150-158. https://doi.org/10.4236/msa.2016.73015

[6] Monteiro, M.S.S.B., Chávez, F.V., Sebastião, P.J. and Tavares, M.I.B. (2013) ${ }^{1} \mathrm{H}$ NMR Relaxometry and X-Ray Study of PCL/Nevirapine Hybrids. Polymer Testing, 32, 553-566. https://doi.org/10.1016/j.polymertesting.2013.01.016

[7] Sebastião, P.J., Monteiro, M.S.S.B., Brito, L.M., Rodrigues, E., Chávez, F. and Tavares, M.I.B. (2016) Conventional and Fast Field Cycling Relaxometry Study on the Molecular Dynamics in Polymer Nanocomposites for Use as Drug Delivery System. Journal of Nanoscience and Nanotechnology, 16, 7539-7545. https://doi.org/10.1166/jnn.2016.12476

[8] Almeida, A.S., Tavares, M.I.B., Silva, E.O., Neto, R.P.C. and Moreira, L.A. (2012) Development of Hybrid Nanocomposites Based on PLLA and Low-Field NMR Characterization. Polymer Testing, 31, 267-275. 
https://doi.org/10.1016/j.polymertesting.2011.11.005

[9] Mofokeng, J. and Luyt, A.S. (2015) Dynamic Mechanical Properties of PLA/PHBV, PLA/PCL, PHBV/PCL Blends and Their Nanocomposites with $\mathrm{TiO}_{2}$ Nanofiller. Thermochimica Acta, 613, 41-53. https://doi.org/10.1016/j.tca.2015.05.019

[10] Shi, R., Magaye, R., Castranova, V. and Zhao, J. (2013) Titanium Dioxide Nanoparticles: A Review of Current Toxicological Data. Particle and Fiber Toxicology, 10, 2-33. https://doi.org/10.1186/1743-8977-10-15

[11] Mofokeng, J.P. and Luyt, A.S. (2015) Morphology and Thermal Degradation Studies of Melt-Mixed Poly(Lactic Acid) (PLA)/Poly( $\varepsilon$-Caprolactone) (PCL) Biodegradable Polymer Blend Nanocomposite with $\mathrm{TiO}_{2}$ as Filler. Polymer Testing, 45, 93-100. https://doi.org/10.1016/j.polymertesting.2015.05.007

[12] Pena, J.A., Gutiérrez, S.J., Villamil, J.C., Agudelo, N.A. and Pérez, L.D. (2016) Policaprolactone/Polivinylpyrrolidone/Siloxane Hybrids Materials: Synthesis and in vitro Delivery of Diclofenac and Biocompatibility with Periodontal Ligament Fibroblasts. Materials Science and Engineering C, 58, 60-69. https://doi.org/10.1016/j.msec.2015.08.007

[13] Wu, C.S. (2004). In situ Polymerization of Titanium Isopropoxide in Polycaprolactone: Properties and Characterization of the Hybrid Nanocomposites. Journal of Applied Polymer Science, 92, 1749-1757. https://doi.org/10.1002/app.20135

[14] Enose, A.A., Dasan, P.K., Sivaramakrishnan, H. and Shah, S.M. (2014) Formulation and Characterization of Solid Dispersion Prepared by Hot Melt Mixing: A Fast Screening Approach for Polymer Selection. Journal of Pharmaceutical, 2014, 1-13. https://doi.org/10.1155/2014/105382

[15] Monteiro, M.S.S.B., Lunz, J., Sebastião, P.J. and Tavares, M.I.B. (2016) Evaluation of Nevirapine Release Kinetics from Polycaprolactone Hybrids. Materials Science and Applications, 7, 680-701. https://doi.org/10.4236/msa.2016.711055

[16] Monteiro, M.S.S.B., Rodrigues, C.L., Neto, R.C. and Tavares, M.I.B. (2012) The Structure of Polycaprolactone-Clay Nanocomposites Investigated by ${ }^{1} \mathrm{H}$ NMR Relaxometry. Journal of Nanoscience and Nanotechnology, 12, 7307-7313. https://doi.org/10.1166/jnn.2012.6431

[17] Nakamoto, K. (1997) Theory and Applications in Inorganic Chemistry: Infrared and Raman Spectra of Inorganic and Coordination Compound. 5th Edition, John Wiley, Hoboken.

[18] Li, R., Nie, K., Shen, X. and Wang, S. (2007) Biodegradable Polyester Hybrid Nanocomposites Containing Titanium Dioxide Network and Poly( $\varepsilon$-Caprolactone): Synthesis and Characterization. Materials Letter, 61, 1368-1371. https://doi.org/10.1016/j.matlet.2006.07.032

[19] Castillho, A.C. and Alarcón, J.G.O. (2011) Preparation and Characterization of Hybrids Materials of Epoxy Resin Type Bisphenol A with Silicon and Titanium Oxides by Sol Gel Process. Journal of Mexican Chemical Society, 55, 233-238.

[20] Rodrigues, E.C., Soares, L.A., Júnior Modenes, M.A., Sene, J.J., Bannach, G., Carvalho, C.T. and Ionashiro, M. (2011) Synthesis and Characterization of Fe(III)-Doped Ceramic Membranes of Titanium Dioxide and Its Application in Photoelectrocatalysis of a Textile Dye. Eclética Quimica, 36, 18-36. https://doi.org/10.1590/S0100-46702011000100002

[21] Clemens, P., Wei, X., Wilson, B.L. and Thomas, R.L. (2013) Anatase Titanium Dioxide Coated Single Wall Carbon Nanotubes Manufactured by Sonochemical-Hydrothermal Technique. Open Journal of Composite Materials, 3, 21-32. 
https://doi.org/10.4236/ojcm.2013.32A004

[22] Rashidzadeh, M. (2008) Synthesis of High-Thermal Stable Titanium Dioxide Nanoparticles. International Journal of Photoenergy, 2008, 1-4. https://doi.org/10.1155/2008/245981

[23] Bagheri, S., Shameli, K. and Hamid, S.B.A. (2013) Synthesis and Characterization of Anatase Titanium Dioxide Nanoparticles Using Egg White Solution via Sol-Gel Method. Journal of Chemistry, 2013, 1-5. https://doi.org/10.1155/2013/848205

[24] Narayan, H. and Alemu, H. (2017) A Comparison of Photocatalytic Activity of $\mathrm{TiO}_{2}$ Nanocomposites Doped with $\mathrm{Zn}^{2+/} \mathrm{Fe}^{3+}$ and $\mathrm{Y}^{3+}$ Ions. International Journal of $\mathrm{Na}$ noscience Nanotechnology, 13, 315-325.

[25] Mirzaei, M., Ahadi, H., Shariaty-Niassar, M. and Akbari, M. (2015) Fabrication and Characterization of Visible Light Active $\mathrm{Fe}-\mathrm{TiO}_{2}$ Nanocomposites as Nanophotocatalyst. International Journal of Nanoscience Nanotechnology, 11, 289-293.

[26] Tamjid, E., Bagheri, R., Vossoughi, M. and Simchi, A. (2011) Effect of $\mathrm{TiO}_{2}$ Morphology on in vitro Bioactivity of Polycaprolactone/ $\mathrm{TiO}_{2}$ Nanocomposites. Materials Letters, 65, 2530-2533. https://doi.org/10.1016/j.matlet.2011.05.037

[27] Nandagopal, S., Robin, A., Soney, C.G., Jayachandran, V.P., Nandakumar, K. and Sabu, T. (2016) Gentamicin Loaded Electrospun Poly( $\varepsilon$-Caprolactone)/ $/ \mathrm{TiO}_{2}$ Nanocomposite Membranes with Antibacterial Property against Methicillin Resistant Staphylococcus aureus. Journal Polymer-Plastics Technology and Engineering, 55, 1785-1796. https://doi.org/10.1080/03602559.2016.1171877

[28] Li, R., Nie, K., Pang, W. and Qingren, Z. (2007) Morphology and Properties of Organic-Inorganic Hybrid Materials Involving $\mathrm{TiO}_{2}$ and Poly( $\varepsilon$-Caprolactone), a Biodegradable Aliphatic Polyester. Journal of Biomedical Research Part A, 83, 114-122. https://doi.org/10.1002/jbm.a.31224

[29] Bajsić, E.G., Bulatović, V.O., Slouf, M. and Šitum, A. (2014) Characterization of Biodegradable Polycaprolactone Containing Titanium Dioxide Micro and Nanoparticles. International Journal of Materials and Metallurgical Engineering, 8, 611-615. 